\title{
A case of immune reconstitution syndrome complicating progressive multifocal leukoencephalopathy after kidney transplant: Clinical, pathological, and radiographic features
}

\author{
Eric Jackowiak $^{1}$ (D) | Nirav Shah ${ }^{2}$ | Huiwen Chen ${ }^{2}$ | Ajitesh Ojha ${ }^{1}$ | John Doyle ${ }^{1}$ | \\ Anne Shepler $^{3}$ | Tatiana Bogdanovich ${ }^{4}$ | Fernanda P. Silveira ${ }^{4}$ Ghady Haidar ${ }^{4}$ (i)
}

\author{
${ }^{1}$ Department of Neurology, University of \\ Pittsburgh Medical Center, Pittsburgh, \\ Pennsylvania \\ ${ }^{2}$ Division of Nephrology, University of \\ Pittsburgh Medical Center, Pittsburgh, \\ Pennsylvania \\ ${ }^{3}$ Department of Pathology, University of \\ Pittsburgh Medical Center, Pittsburgh, \\ Pennsylvania \\ ${ }^{4}$ Division of Infectious Diseases, University \\ of Pittsburgh Medical Center, Pittsburgh, \\ Pennsylvania \\ Correspondence \\ Ghady Haidar, Division of Infectious \\ Diseases, University of Pittsburgh and \\ UPMC, 3601 Fifth Avenue, Falk Medical \\ Building, Suite 5B, Pittsburgh, PA 15213. \\ Email: haidarg@upmc.edu \\ Present address \\ Eric Jackowiak, Department of \\ Neurology, University of Michigan Medical \\ School, Ann Arbor, Michigan
}

\begin{abstract}
Progressive multifocal leukoencephalopathy (PML) is a life-threatening central nervous system (CNS) disorder, most commonly described in patients infected with the human immunodeficiency virus (HIV). Limited data exist on its natural history and treatment in solid organ transplant (SOT) recipients. A complication of PML is the immune reconstitution inflammatory syndrome (IRIS), which develops after T cell reconstitution and can have severe consequences when it occurs in the CNS. While well described in HIV-infected individuals, its clinical features, diagnosis, and treatment after SOT are largely unknown. We report a case of a kidney transplant recipient who was diagnosed with PML and developed significant worsening of her symptoms upon reduction of immunosuppression. Thallium SPECT showed avid uptake suggestive of lymphoma, but the diagnosis of PML-IRIS was ultimately established by brain biopsy. She survived with nearly complete restoration of her functional status after a prolonged steroid taper.
\end{abstract}

KEYWORDS

immune reconstitution inflammatory syndrome (IRIS), JC virus, progressive multifocal leukoencephalopathy (PML), renal transplant, solid organ transplant, thallium SPECT scan

\section{1 | INTRODUCTION}

Progressive multifocal leukoencephalopathy (PML) is a demyelinating central nervous system (CNS) disorder caused by reactivation of the John Cunningham (JC) virus in the setting of immune suppression. Progressive multifocal leukoencephalopathy was first described in patients with hematological malignancies ${ }^{1}$ but became better recognized in the 1980s during the acquired immunodeficiency syndrome (AIDS) epidemic. latrogenic immunosuppression (particularly the monoclonal antibody natalizumab), solid organ transplantation (SOT), and hematopoietic cell transplantation (HCT) are also established risk factors. ${ }^{2-4}$ Reversal of the patient's underlying immune deficiency can lead to a paradoxical clinical worsening called the immune reconstitution inflammatory syndrome (IRIS), which is characterized by severe inflammation and marked CNS infiltration with cytotoxic T cells. ${ }^{4-6}$ PML-IRIS can conceivably occur in SOT recipients whose immunosuppression is reduced but has been scarcely reported in this setting. Additionally, data on the outcomes and management of PML-IRIS among SOT recipients are sparse. ${ }^{2}$ Herein, we present a case of a patient with PML after kidney transplant who developed severe IRIS during her treatment course. We highlight the diagnostic workup obtained, including a thallium SPECT scan and brain biopsy, and review the literature on PML and PML-IRIS, their diagnosis, and their treatments 
in SOT. We also comment on the utility of SPECT scans in distinguishing PML and PML-IRIS from CNS malignancies.

\section{2 | CASE PRESENTATION}

The patient was a 60-year-old woman with a history of deceased donor renal transplant performed for IgA nephropathy 9 years prior to presentation. She received alemtuzumab induction. She had no infectious complications or recent immunosuppression augmentation for rejection. Her transplant-related medications at the time of evaluation were tacrolimus, mycophenolate mofetil, and trimethoprim-sulfamethoxazole.

She presented with 2 months of progressively worsening wordfinding difficulty, specifically with the inability to name familiar places and objects (Figure 1). She denied any effect on other cognitive domains. However, on bedside evaluation she had compromised executive functioning (unable to perform trails assessment), attention (could repeat numbers forward but not backward), language (unable to repeat sentences, difficulty with naming), and delayed recall (named zero of five objects at five minutes). At that time, her strength, sensation, and coordination were preserved. Serum creatinine was $2.3 \mathrm{mg} / \mathrm{dL}$, around her baseline. She had mild leukopenia and lymphopenia with a white blood cell count of 2900 cells/L and an absolute lymphocyte count of around 600 cells/L, both at her baseline. The rest of her laboratory tests were unremarkable.

Non-contrasted magnetic resonance imaging (MRI) of the brain identified multifocal T2 signal hyperintensities in the left posterior temporal and parietal lobes, cingulate gyrus, and splenium of the corpus callosum (Figure 2). There was minimal associated mass effect and no areas of restricted diffusion. She subsequently had cerebrospinal fluid (CSF) analysis, which was notable for one white blood cell per highpower field, zero red blood cells, glucose of $91 \mathrm{mg} / \mathrm{dL}$ (serum $68 \mathrm{mg}$ / $\mathrm{dL}$ ), and protein of $46 \mathrm{~g} / \mathrm{dL}$. Cerebrospinal fluid JC virus polymerase chain reaction (PCR) was positive, but at $<10$ copies $/ \mathrm{mL}$. Cerebrospinal fluid cytology was negative for malignant cells. Human immunodeficiency virus (HIV) and Epstein-Barr virus (EBV) testing were negative.

She was diagnosed with PML and was initially managed by discontinuation of mycophenolate alone (Figure 1). After further discussion with the patient and her family, the decision was made to slowly wean tacrolimus as a potentially lifesaving measure, knowing that this would likely lead to rejection of her allograft. Approximately 5 weeks later, tacrolimus was discontinued entirely. She was started on mirtazapine $15 \mathrm{mg}$ daily, based on limited case reports of its possible utility among patients with $\mathrm{PML}$, including our own experience with a lung transplant recipient from our institution who received this drug and improved. ${ }^{7,8}$

Around this time, she developed significant worsening of her language skills and had new symptoms of motor weakness and unsteady
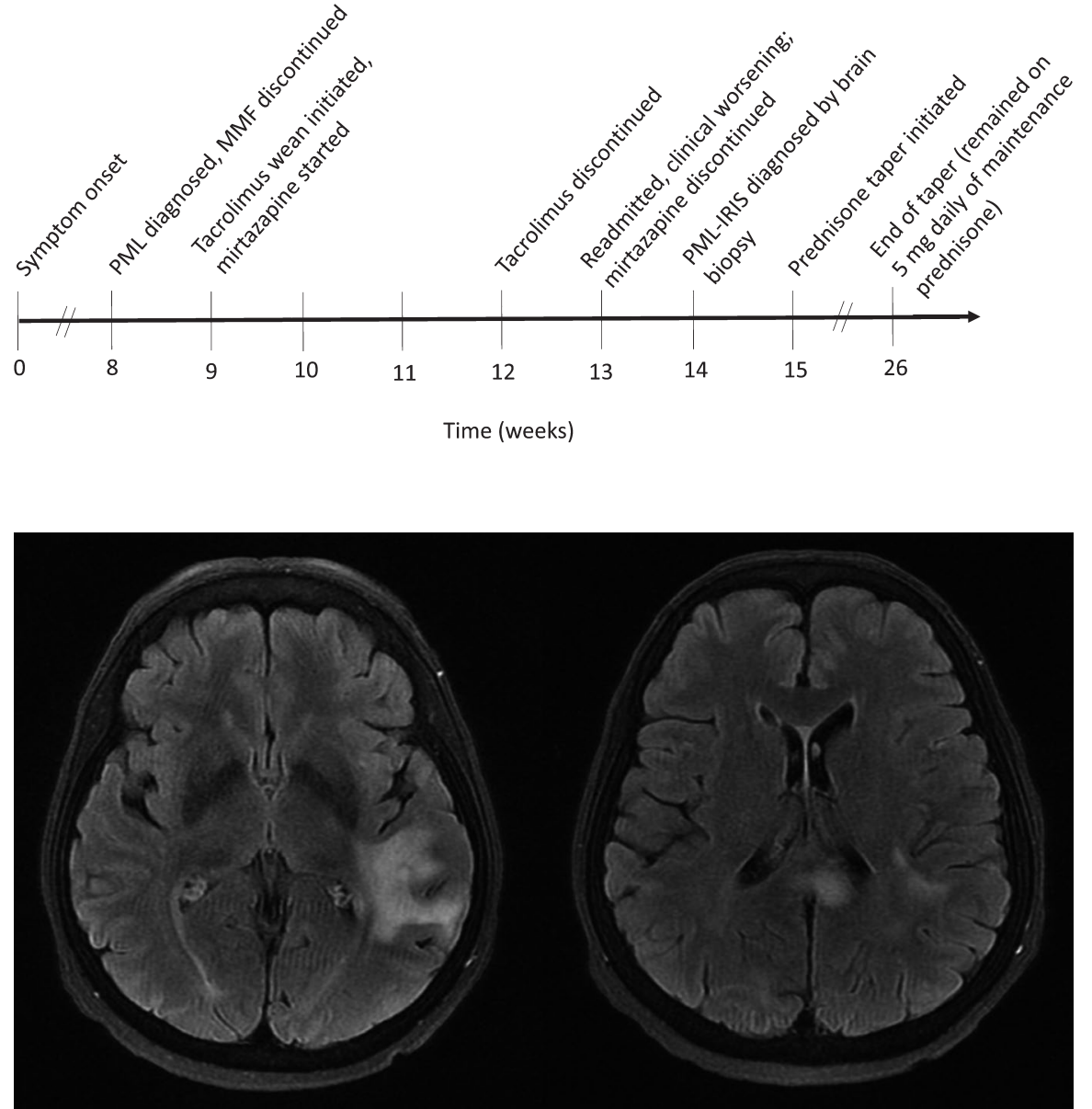

FIGURE 1 Timeline of events; IRIS, immune reconstitution inflammatory syndrome; MMF, mycophenolate mofetil; PML, progressive multifocal leukoencephalopathy
FIGURE 2 Initial brain MRI without contrast. Sequences shown are T2 FLAIR images, demonstrating hyperintensities in the left temporal and parietal lobes and in the splenium of the corpus callosum 
gait (Figure 1). She deteriorated further, with right hemiparesis, inability to walk, unintelligible speech, and progressive cognitive deficits including an inability to follow simple commands. Mirtazapine was initially decreased to $7.5 \mathrm{mg}$ due to sedation and then ultimately stopped about 1 month after its initiation. A brain MRI without contrast showed progression of T2 white matter signal change in the existing areas and new areas involving the right temporal lobe, right insula, and left subthalamic nucleus (Figure 3). Contrast imaging was not obtained due to the risk of nephrogenic systemic fibrosis, at the recommendation of the transplant nephrology team. Differential diagnosis at the time included worsening of PML, development of IRIS, or an alternative diagnosis such as CNS post-transplant lymphoproliferative disorder (PTLD).

Based on literature demonstrating the potential utility of thallium imaging in differentiating PML from CNS lymphoma among HIV-infected patients, ${ }^{9}$ a thallium SPECT scan was performed. This revealed increased thallium uptake in her known white matter lesions, suggesting the presence neoplastic process such as PTLD rather than PML (Figure 4). However, her subsequent CSF had a higher JC virus copy count (29 copies/mL). Ultimately, a biopsy of the left frontal lesion was performed and showed foci of demyelination, oligodendrocytes with enlarged nuclei containing viral inclusions, and reactive, bizarre-appearing astrocytes. The viral inclusions were positive for the JC virus by in situ hybridization (ISH), confirming the diagnosis of PML (Figure 5). Additionally, histology revealed a $T$ cell and plasma cell inflammatory response, consistent with IRIS (Figure 6). She was treated with a prolonged oral steroid taper for IRIS, starting with 4 mg every 6 hours of dexamethasone ( 2 days), followed by an 11-week prednisone taper as follows: $60 \mathrm{mg}$ daily for 1 week, followed by $55 \mathrm{mg}$ daily for 1 week, $50 \mathrm{mg}$ daily for 1 week, $45 \mathrm{mg}$ daily for 1 week, $35 \mathrm{mg}$ daily for 3 weeks, $25 \mathrm{mg}$ daily for 2 weeks, and finally $15 \mathrm{mg}$ daily for 2 weeks. After this, her prednisone dose was reduced to $5 \mathrm{mg}$ daily, on which she remains in order to avoid allograft inflammation (Figure 1). Three months later, she was able to walk independently and had regained much of her language fluency. Interval MRI showed improvement in the white matter abnormalities. She resumed hemodialysis around 1 year after her initial diagnosis with PML. As of the writing of this manuscript, it has been nearly 2 years since she first presented. She is currently doing well and is nearly neurologically intact, with minimal residual speech impairment.

\section{3 | DISCUSSION}

Progressive multifocal leukoencephalopathy is uncommon in transplant recipients but is associated with a poor prognosis. The largest
FIGURE 3 Follow-up brain MRI without contrast after clinical worsening. Sequences shows are T2 FLAIR, demonstrating interval progression of hyperintensities now with mass effect and spread to new brain regions

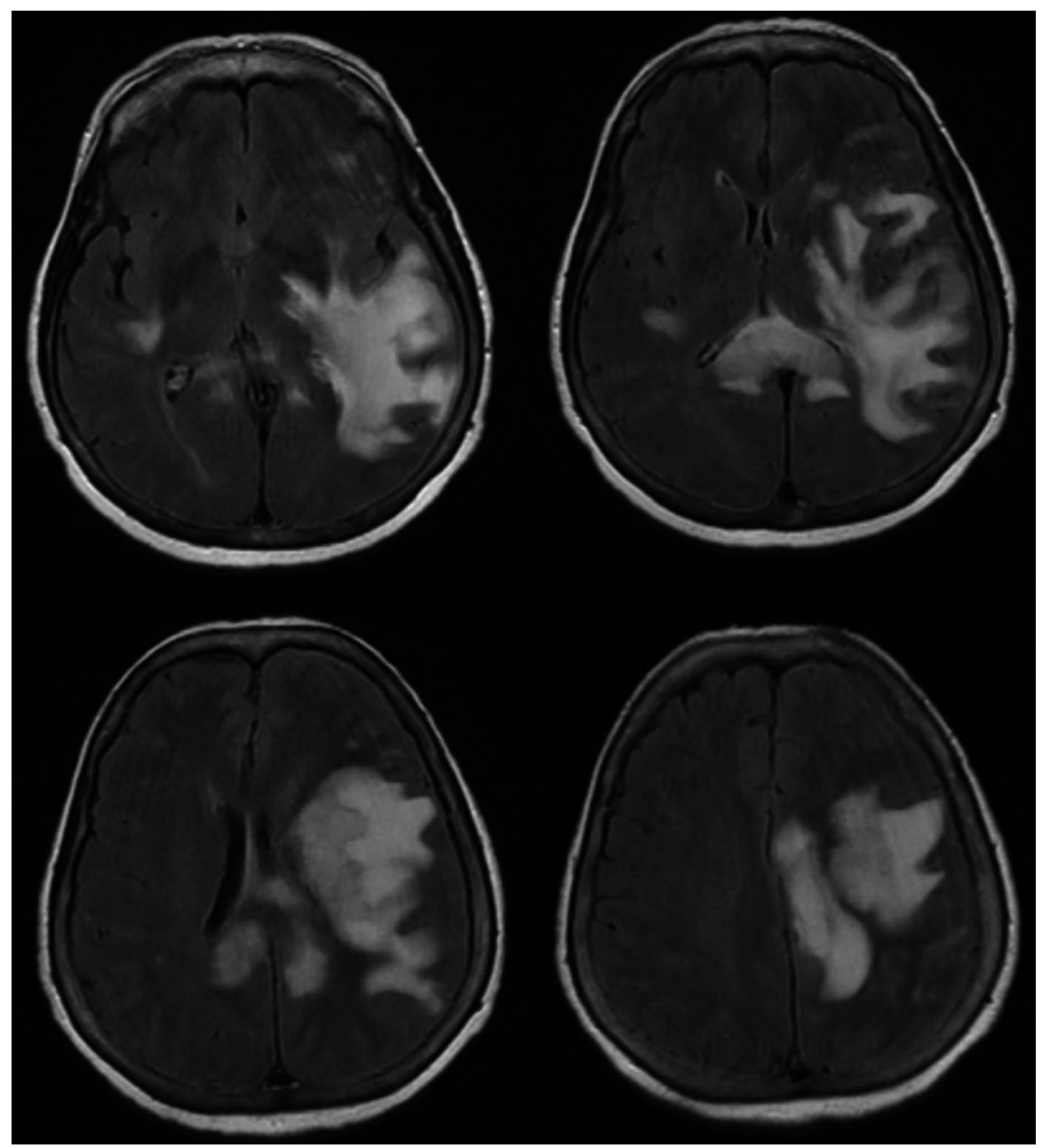


study of PML after transplantation was a 2011 multicenter review of 69 patients, of whom 64\% (44/69) were SOT recipients. ${ }^{2}$ Kidney transplants were the most common $(n=22)$, followed by liver ( $n=10)$, lung $(n=6)$, and heart transplants $(n=6)$. All patients were diagnosed either by brain biopsy, CSF JC virus PCR, or autopsy. The median time to development of PML symptoms following transplantation was 17 months but ranged widely from $<1$ month to more than 20 years. Interestingly however, the hazard ratio of developing PML after SOT was greatest in the immediate post-transplant period, suggesting that heightened immunosuppression from recent antibody induction and generally higher troughs of calcineurin inhibitors and high doses of antiproliferative agents may confer an increased risk of reactivation early after transplant. ${ }^{2}$ Nonetheless, later cases can also occur even without any immunosuppression augmentation, such as the case with our patient. The median time from symptom onset to death after SOT was 6.4 months after SOT (range $<1$ month to

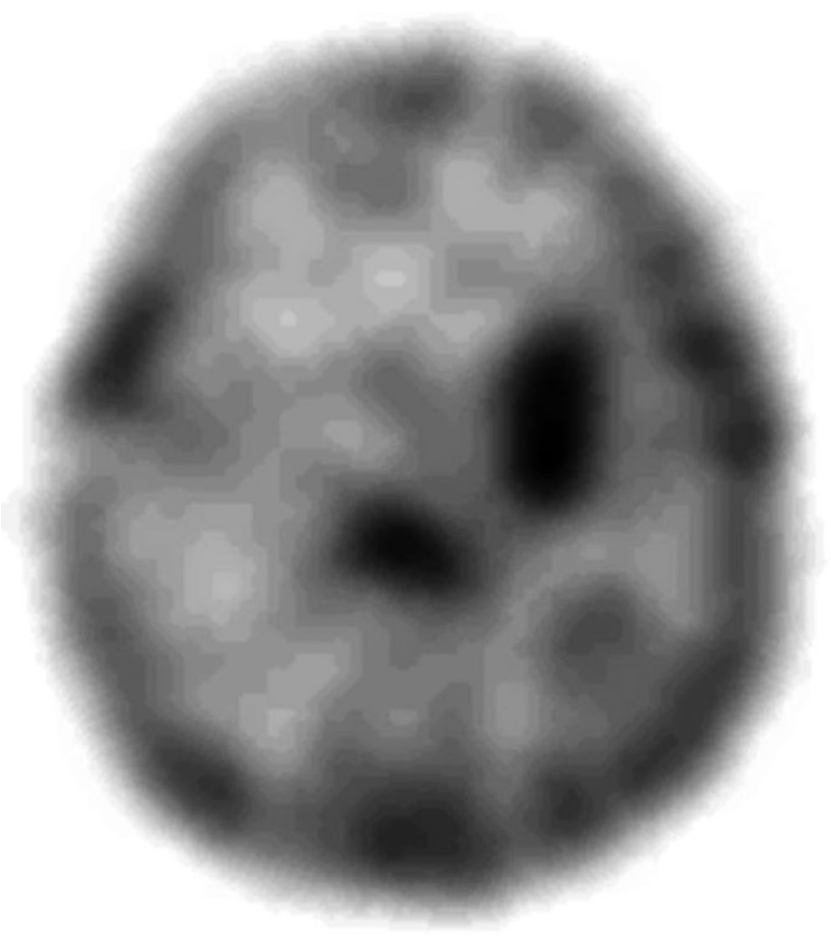

FIGURE 4 Thallium SPECT showing increased thallium uptake in regions corresponding to abnormalities on prior MRI
$>37$ months), and the overall fatality rate was $84 \% .^{2}$ As is the case with HIV-infected individuals, the most common presenting symptoms were cognitive deficits, followed by weakness, visual disturbances, gait disorders, personality changes, aphasia, and seizures.

Elimination of iatrogenic immunosuppression remains the mainstay of treatment after transplantation, though this may lead to graft loss. While graft failure is fatal in patients with life-sustaining organ transplants such as lungs, livers, and hearts, kidney transplant recipients have the option of resuming dialysis. Nonetheless, data on the management of PML after SOT are largely derived from case series and case reports. In the aforementioned study, ${ }^{2} 55 \%$ (24/44) of SOT recipients received some form of treatment for PML. Of these 24 patients, $79 \%(19 / 24)$ had their immunosuppression reduced, either as the sole intervention ( $\mathrm{n}=9$ ) or in combination with adjunctive medical therapy $(n=10)$. Medications given to SOT recipients with PML included cytarabine $(n=8)$, mirtazapine $(n=4)$, cidofovir $(n=2)$, mefloquine $(n=2)$, interferon-alpha $(n=1)$, ganciclovir $(n=1)$, and the antiviral agent tilorone $(n=1)$, either alone or in combination. Despite these efforts, no intervention had any clear impact on prognosis or survival. In more contemporary case reports, reduction of immunosuppression continues to be the most common treatment modality, ${ }^{10-12}$ though mirtazapine was successfully used in one case of a lung transplant recipient. ${ }^{8}$

Mirtazapine, which inhibits JC virus cell entry by blocking the $\mathrm{JC}$ virus serotonin receptor $5 \mathrm{HT} 2 \mathrm{a}$, was successfully used in four HIV-infected individuals with PML, ${ }^{7}$ though its contribution to their clinical improvement is unclear as all four patients were also receiving antiretroviral therapy (ART). In addition, while a lung transplant recipient with JC virus encephalopathy improved with mirtazapine, ${ }^{8}$ her MMF was also discontinued, and mirtazapine was eventually stopped due to drowsiness. Despite these potentially promising case reports, a 2016 meta-analysis of five cohort studies and 74 case reports (with only seven SOT recipients identified) found that mirtazapine had no effect on clinical outcome, which was largely driven by the presence of immunosuppression, hematological malignancy, or transplant. ${ }^{13}$ Nonetheless, the dismal prognosis of PML and the generally benign safety profile of mirtazapine prompted us to administer it to our patient as adjunctive treatment, though it did not lead to any clinical improvement and in fact may have contributed to increased somnolence when she developed IRIS.

Due to the absence of any effective antiviral agent to treat $J C$ virus infections, there has been immense interest in the use of

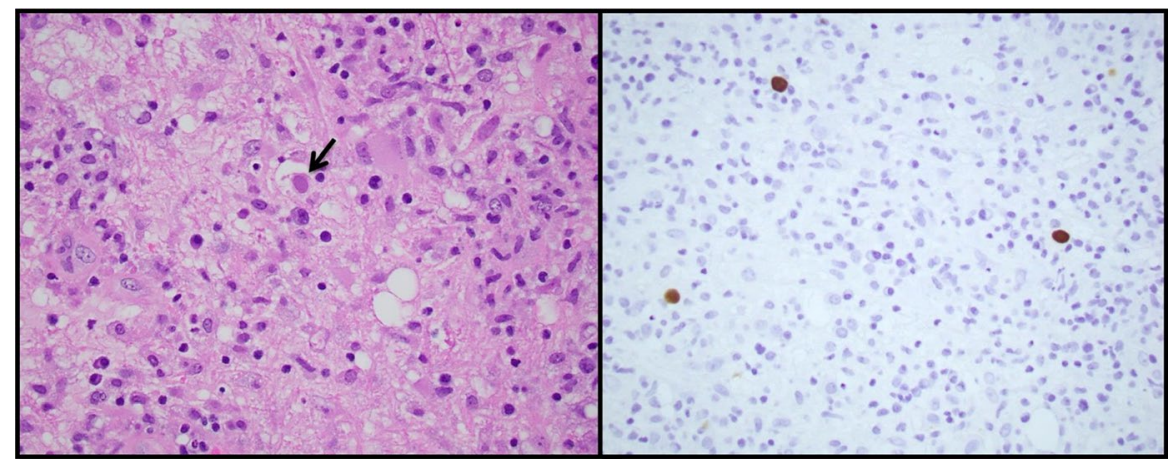

FIGURE 5 Hematoxylin and eosin (H\&E) stained section shows an oligodendrocyte with an enlarged nucleus containing a viral inclusion (arrow) in a demyelinated area containing reactive astrocytes (original magnification $\times 400$ ). A JC virus in situ hybridization (ISH) study shows scattered positive nuclei (original magnification $\times 400$ ) 
FIGURE 6 H\&E stained section shows a dense inflammatory infiltrate composed of T cells (CD3+) and plasma cells (CD138+) with only rare $B$ cells (CD20+); original magnification $\times 400$

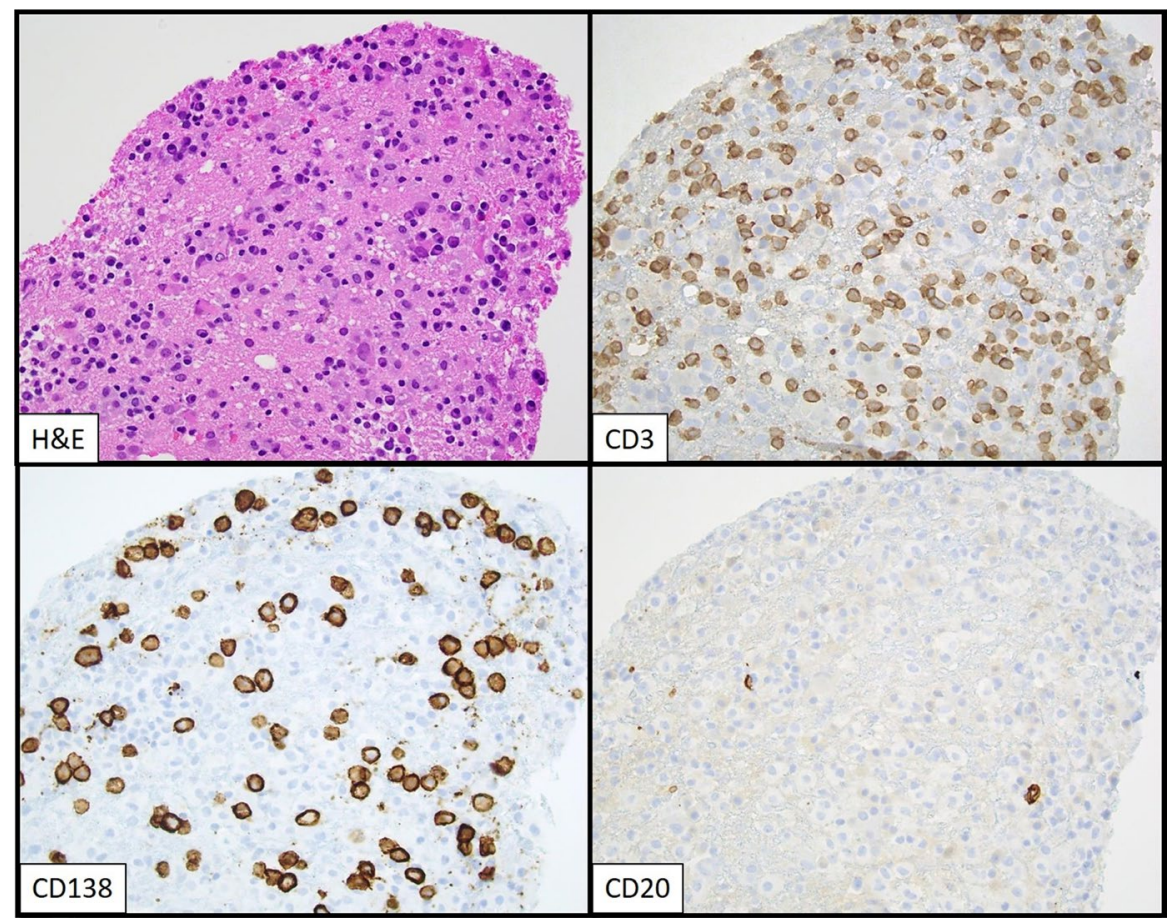

immunomodulatory therapy for the treatment of PML. For instance, interleukin-7 in combination with a JC virus capsid vaccine resulted in CSF JC viral load clearance, MRI improvement, and clinical stabilization of two patients with primary or acquired CD4 lymphopenia, though neither of these agents are readily available, and their benefit remains speculative. ${ }^{14}$ One potential drug target is programmed cell death protein 1 (PD-1), which is a negative regulator of the immune response that is upregulated on CD4+ and CD8+ cells in patients with PML, and which may contribute to impaired JC viral clearance. ${ }^{15}$ In a recent study of eight patients with PML (four with hematological malignancies, two with HIV, and two with idiopathic lymphopenia) treated with the PD-1 inhibitor pembrolizumab, five patients had varying degrees of clinical, virological, and radiographic improvement or stabilization, which correlated with the emergence of a strong anti-JC virus cell-mediated immune responses. ${ }^{15}$ One patient had already improved prior to receiving pembrolizumab, and two (one with idiopathic lymphopenia and one with non-Hodgkin's lymphoma) deteriorated despite receiving it. No patient in this cohort developed IRIS. Larger randomized trials are required to determine the effect of pembrolizumab on the natural history and prognosis of PML.

Allogeneic adoptive JC virus-specific T cell transfer is another emerging treatment modality. In a recent small study, investigators administered third-party, closely HLA-matched BK-virus-specific T cells to three patients with PML (one with a cord blood transplant, one with myeloproliferative disorder, and one with advanced HIV). ${ }^{16}$ Results were mixed, with one patient achieving complete clinical, radiographic, and virological remission, and two only achieving a partial response. In addition, one of these patients had virological improvement but clinical deterioration and was thus transitioned to hospice. The latter two patients developed IRIS, which was thought to have been directly mediated by the virus-specific T cells. Larger studies are clearly needed to confirm the efficacy of this approach and to ascertain the true incidence and consequences of IRIS with adoptive $T$ cell transfer. In addition, certain challenges related to the development of adoptive T cell therapies (eg, donor availability, HLA matching, and product generation time) must be overcome for such a treatment modality to become commonplace. ${ }^{17}$ A clinical trial of adoptive T cell therapy for PML is underway (NCT02694783).

Diagnostic evaluation of PML includes neuroimaging and CSF analysis for the detection of JC virus DNA, though large studies of the performance of the JC virus CSF PCR among SOT recipients have not been performed. Studies of HIV-infected individuals with PML have shown that PCR has a sensitivity and specificity of $72 \%-92 \%$ and $92 \%-100 \%$, respectively. ${ }^{18-23}$ However, PCR is less sensitive in patients receiving ART vs those who are ART naïve (59\% vs $90 \%$ sensitivity, respectively), which is thought to be a marker of heightened immune reconstitution among persons on ART, resulting in reduced JC viral replication. ${ }^{24}$ Our patient had an extremely low initial CSF JC virus copy count of $<10$ copies/mL. Indeed, the CSF viral load can vary widely, from $10^{2}$ copies $/ \mathrm{mL}$ to $>10^{7}$ copies $/ \mathrm{mL},{ }^{24}$ though more pronounced extremes have also been described. For instance, in one study of 28 patients with natalizumab-associated PML, 50\% of patients had CSF JC virus viral loads of $<500$ copies $/ \mathrm{mL}$ when performed by a commercial assay, ${ }^{25}$ with a median of 62.5 copies/ $\mathrm{mL}$ (range 0-500 copies/mL). Furthermore, CSF JC viral loads were markedly different when performed using a more sensitive assay at the National Institutes of Health research laboratory. Inter-laboratory variability in JC virus PCR performance is expected to vary, due to differences in the platforms, primers, and amplified DNA regions used. Thus, as is the case with our patient, low and even negative JC virus CSF viral loads may be misleading but do not rule out PML, and 
false-negative results do rarely occur. ${ }^{18}$ In such situations in which CSF testing is negative or equivocal, brain biopsy can be used to definitively prove the diagnosis. ${ }^{18}$ However, despite the low-positive initial CSF JC virus PCR in our patient, the clinical and radiographic findings were all compatible with PML, obviating the need for a brain biopsy during the initial stage of her illness. False-positive JC viral loads have been rarely described among patients with multiple sclerosis, occurring at rates of $1 \%-5 \%{ }^{26,27}$

Immune reconstitution inflammatory syndrome is a severe complication of PML and is characterized by infiltration of the brain with activated $T$ cells, resulting in brain edema, mass effect, herniation, and death. ${ }^{4,6}$ PML-IRIS is well described in HIV-infected individuals receiving $A R T,{ }^{5}$ as well as in patients with natalizumab-related PML after the discontinuation of natalizumab and initiation of plasmapheresis. ${ }^{28}$ In contrast, PML-IRIS after SOT has been infrequently reported $^{2}$ and as demonstrated by our case can be precipitated by even a slow taper of immunosuppression. Data on management are sparse, and while steroids have been used in HIV-related PML-IRIS, their benefit is unproven. ${ }^{28}$ We were only able to identify two other cases evaluating the treatment of PML-IRIS after SOT. In a report of a liver transplant recipient, the diagnosis was made based on paradoxical worsening of the patient's MRI findings after reduction of immunosuppression, and the patient survived after a steroid taper. ${ }^{29}$ The other patient was a lung transplant recipient whose CD4 count increased and MRI findings worsened after reduction of immunosuppression. She was treated with mefloquine without steroids, and she did not survive. ${ }^{2}$ Our patient had a favorable outcome after an 11-week steroid taper.

The diagnosis of PML-IRIS remains challenging. Gadoliniumenhanced brain MRIs can show enlarged white matter lesions, commonly with contrast enhancement due to local inflammation and breakdown of the blood-brain barrier. ${ }^{3,4}$ We avoided gadolinium in our patient due to her progressively worsening renal disease and risk of nephrogenic systemic fibrosis, although contemporary data suggest that this risk is low with newer gadolinium agents. ${ }^{30}$ Brain biopsy can reveal characteristic pathological findings for both PML and PML-IRIS. ${ }^{4}$ Given the inherent risks of a brain biopsy and our reluctance to pursue a contrast-enhanced MRI due to poor renal function, we performed a thallium SPECT to attempt to differentiate PML from PTLD or another neoplastic process. Indeed, the 2013 American Academy of Neurology (AAN) consensus recommendations on PML diagnostic criteria acknowledge that the presence of increased thallium uptake is typically seen in CNS lymphomas but not usually in PML. ${ }^{31}$ Their recommendations are based on a single-center study of eight patients with advanced HIV, six of whom had PML and two of whom had primary CNS Iymphoma, wherein SPECT studies showed lack of uptake among all patients with PML but intense uptake among both patients with lymphoma. ${ }^{9}$ However, the AAN considers its utility to be limited, given the widespread use of contrasted MRI imaging and the presence of a few false-positive results in the literature. ${ }^{32}$ Our patient's thallium SPECT showed avid thallium uptake, which may have been confounded by the concomitant presence of IRIS. To our knowledge, this is the first report of a thallium SPECT scan in a patient with PML-IRIS. Indeed, the literature on thallium scans has focused mainly on differentiating $P M L$ and not PML-IRIS from malignancy, and the performance of thallium SPECT in an inflammatory state like PML-IRIS is unknown. We hypothesize that the reason for the positive SPECT was because at the time it was obtained, the patient had PML-IRIS and not simply PML, with lesions in the former expected to be inflamed and hypermetabolic, in contrast with lesions in the latter. More research is needed to determine the accuracy of thallium SPECT as a diagnostic tool for both PML and PML-IRIS, particularly to reduce the need of brain biopsies.

In conclusion, $\mathrm{PML}$ remains a rare yet nearly universally fatal disorder in SOT. Contemporary data are required to define its current epidemiology, prognosis and the role of medical therapy, be it reduction of immunosuppression or hitherto unproven interventions. Large-scale studies of innovative agents such as PD-1 inhibitors and adoptive $T$ cell therapy should also include transplant recipients. A high index of suspicion for PML-IRIS should be maintained in transplant recipient recipients with paradoxical worsening of their PML after reduction in immunosuppression. Characteristic MRI changes are suggestive of the diagnosis, while the performance of thallium SPECT is largely unknown. A brain biopsy is usually diagnostic. Steroids may be lifesaving in cases of CNS IRIS, though data to support their use are limited.

\section{CONFLICT OF INTEREST}

The authors of this report have no conflicts of interest to disclose.

\section{AUTHORS' CONTRIBUTION}

EJ and $\mathrm{GH}$ were responsible for writing the initial drafts of the manuscript. EJ, $\mathrm{AO}$, and $\mathrm{GH}$ responded to the reviewers' comments and contributed to the revisions. $\mathrm{GH}$ supervised all steps of manuscript preparation. NS, HC, AO, JD, AS, TB, and FPS were responsible for reviewing the article, suggesting modifications to the text, and for final approval of the manuscript.

\section{ORCID}

Eric Jackowiak iD https://orcid.org/0000-0001-8316-9781

Ghady Haidar (iD https://orcid.org/0000-0003-0634-8211

\section{REFERENCES}

1. Astrom KE, Mancall EL, Richardson EP Jr. Progressive multifocal leuko-encephalopathy; a hitherto unrecognized complication of chronic lymphatic leukaemia and Hodgkin's disease. Brain. 1958;81(1):93-111.

2. Mateen FJ, Muralidharan R, Carone M, et al. Progressive multifocal leukoencephalopathy in transplant recipients. Ann Neurology. 2011;70(2):305-322. 
3. Tan CS, Koralnik IJ. Progressive multifocal leukoencephalopathy and other disorders caused by JC virus: clinical features and pathogenesis. Lancet Neurol. 2010;9(4):425-437.

4. Bauer J, Gold R, Adams O, Lassmann H. Progressive multifocal leukoencephalopathy and immune reconstitution inflammatory syndrome (IRIS). Acta Neuropathol. 2015;130(6):751-764.

5. Tan K, Roda R, Ostrow L, McArthur J, Nath A. PML-IRIS in patients with HIV infection: clinical manifestations and treatment with steroids. Neurology. 2009;72(17):1458-1464.

6. Bowen L, Nath A, Smith B. CNS immune reconstitution inflammatory syndrome. Handb Clin Neurol. 2018;152:167-176.

7. Cettomai $D$, McArthur JC. Mirtazapine use in human immunodeficiency virus-infected patients with progressive multifocal leukoencephalopathy. Arch Neurol. 2009;66(2):255-258.

8. Hamad Y, Silveira FP, Crespo MM. JC virus encephalopathy in a lung transplant recipient: novel presentation of an old virus. J Heart Lung Transplant. 2017;36(2):244-245.

9. Iranzo A, Martí-Fábregas J, Domingo $P$, et al. Absence of thallium-201 brain uptake in progressive multifocal leukoencephalopathy in AIDS patients. Acta Neurol Scand. 1999;100(2):102-105.

10. Sundbom P, Hubbert L, Serrander L. Progressive multifocal leukoencephalopathy after heart transplantation: 4 years of clinically stable infection on low-dose immunosuppressive therapy. Oxf Med Case Reports. 2017;2017(2):omx003.

11. Rastogi A, Gulati N, Bihari C, et al. JC virus-related progressive multifocal leukoencephalopathy after living-donor liver transplant: a rare case. Exp Clin Transplant. 2019;17(3):414-417.

12. Moreno-Estébanez A, Almeida Velasco J, Pérez-Concha T, González-Pinto T, Gabilondo I. Progressive multifocal leukoencephalopathy 11 years after liver transplantation: a case report. $J$ Neurovirol. 2017;23(6):929-931.

13. Jamilloux $Y$, Kerever S, Ferry T, Broussolle C, Honnorat J, Sève P. Treatment of progressive multifocal leukoencephalopathy with mirtazapine. Clin Drug Investig. 2016;36(10):783-789.

14. Sospedra M, Schippling S, Yousef $S$, et al. Treating progressive multifocal leukoencephalopathy with interleukin 7 and vaccination with JC virus capsid protein VP1. Clin Infect Dis. 2014;59(11): 1588-1592.

15. Cortese I, Muranski P, Enose-Akahata Y, et al. Pembrolizumab treatment for progressive multifocal leukoencephalopathy. N Engl J Med. 2019;380(17):1597-1605.

16. Muftuoglu M, Olson A, Marin D, et al. Allogeneic BK virus-specific T cells for progressive multifocal leukoencephalopathy. N Engl J Med. 2018;379(15):1443-1451.

17. Houghtelin A, Bollard CM. Virus-specific T cells for the immunocompromised patient. Front Immunol. 2017;8:1272.

18. Brew BJ, Davies NW, Cinque P, Clifford DB, Nath A. Progressive multifocal leukoencephalopathy and other forms of JC virus disease. Nat Rev Neurol. 2010;6(12):667-679.

19. Koralnik IJ, Boden D, Mai VX, Lord Cl, Letvin NL. JC virus DNA load in patients with and without progressive multifocal leukoencephalopathy. Neurology. 1999;52(2):253-260.

20. Hammarin AL, Bogdanovic G, Svedhem V, Pirskanen R, Morfeldt L, Grandien M. Analysis of PCR as a tool for detection of JC virus DNA in cerebrospinal fluid for diagnosis of progressive multifocal leukoencephalopathy. J Clin Microbiol. 1996;34(12):2929-2932.
21. Vago L, Cinque P, Sala E, et al. JCV-DNA and BKV-DNA in the CNS tissue and CSF of AIDS patients and normal subjects. Study of 41 cases and review of the literature. J Acquir Immune Defic Syndr Hum Retrovirol. 1996;12(2):139-146.

22. Ryschkewitsch $C$, Jensen $P$, Hou J, Fahle G, Fischer S, Major EO. Comparison of PCR-southern hybridization and quantitative real-time PCR for the detection of JC and BK viral nucleotide sequences in urine and cerebrospinal fluid. J Virol Methods. 2004;121(2):217-221.

23. Cinque $P$, Scarpellini $P$, Vago L, Linde A, Lazzarin A. Diagnosis of central nervous system complications in HIV-infected patients: cerebrospinal fluid analysis by the polymerase chain reaction. AIDS. 1997;11(1):1-17.

24. Marzocchetti A, Di Giambenedetto S, Cingolani A, Ammassari A, Cauda R, De Luca A. Reduced rate of diagnostic positive detection of JC virus DNA in cerebrospinal fluid in cases of suspected progressive multifocal leukoencephalopathy in the era of potent antiretroviral therapy. J Clin Microbiol 2005;43(8):4175-4177.

25. Clifford DB, De Luca A, Simpson DM, Arendt G, Giovannoni G, Nath A. Natalizumab-associated progressive multifocal leukoencephalopathy in patients with multiple sclerosis: lessons from 28 cases. Lancet Neurol. 2010;9(4):438-446.

26. Alvarez-Lafuente R, García-Montojo M, De Las HV, Bartolomé M, Arroyo R. JC virus in cerebrospinal fluid samples of multiple sclerosis patients at the first demyelinating event. Mult Scler. 2007;13(5):590-595.

27. lacobaeus E, Ryschkewitsch C, Gravell M, et al. Analysis of cerebrospinal fluid and cerebrospinal fluid cells from patients with multiple sclerosis for detection of JC virus DNA. Mult Scler. 2009;15(1):28-35.

28. Johnson T, Nath A. Immune reconstitution inflammatory syndrome and the central nervous system. Curr Opin Neurol. 2011;24(3):284-290.

29. Avsenik J, Horvat Ledinek A, Šurlan PK. Progressive multifocal leukoencephalopathy - immune reconstitution inflammatory syndrome (PML-IRIS) in a liver transplant recipient. Mult Scler Rel Disord. 2017;17:135-137.

30. Fraum TJ, Ludwig DR, Bashir MR, Fowler KJ. Gadolinium-based contrast agents: a comprehensive risk assessment. J Magn Reson Imaging. 2017;46:338-353.

31. Berger JR, Aksamit AJ, Clifford DB, et al. PML diagnostic criteria: consensus statement from the AAN Neuroinfectious Disease Section. Neurology. 2013;80(15):1430-1438.

32. Port JD, Miseljic S, Lee RR, et al. Progressive multifocal leukoencephalopathy demonstrating contrast enhancement on MRI and uptake of thallium-201: a case report. Neuroradiology. 1999;41(12):895-898.

How to cite this article: Jackowiak E, Shah N, Chen H, et al. A case of immune reconstitution syndrome complicating progressive multifocal leukoencephalopathy after kidney transplant: Clinical, pathological, and radiographic features. Transpl Infect Dis. 2019;21:e13162. https://doi.org/10.1111/ tid.13162 